\title{
Die diaken in twee kerkordes in die Dordtse tradisie
}

NGTT DEEL 55, NR 3 \& 4, 2014

\section{Strauss, PJ}

Universiteit van die Vrystaat

\section{ABSTRACT \\ The deacon as prescribed in two church orders in the line of the order of Dordt}

The question is whether the church orders of the Christian Reformed Church in North America and the Dutch Reformed Church are in line with the church order of Dordt of 1619 on the character of the office of deacon in church. It is established that all three of them concentrate of the deacon as a ministry of mercy. These words are used by the order of the Christian Reformed Church, but also give a summary of the meaning of the other two church orders on the subject. A distinction is made between the focus of an office in church and the specific office as a practical means to achieve that focus.

\section{ABSTRAK}

Die vraag is of die kerkordes van die Christian Reformed Church in North America en die Nederduitse Gereformeerde Kerk ten opsigte van hulle bepalings oor die aard van die diakenamp in die Dordtse tradisie of dieselfde lyn as die Dortse Kerkorde van 1619 beweeg? Die antwoord is dat al drie ordes na die bediening van die diaken as 'n diens van barmhartigheid verwys. Die Kerkorde van die Christian Reformed Church praat letterlik van hierdie diens as 'n "ministry of mercy". 'n Onderskeid word getref tussen die fokus van 'n amp en die amp as die praktiese gestaltegewing daarvan.

\section{KEYWORDS}

The ministry of mercy, An office with an own character, The peculiarity of the office of the deacon, An anti-hierarchial approach, Deacons part of church government 
STRAUSS, PJ

\section{TREFWOORDE}

Diens van barmhartigheid, Selfstandige amp, Eie aard van diakenwees, 'n Antihiërargiese ingesteldheid, Diakens ook in kerkregering

\section{KONTAKBESONDERHEDE}

\section{Prof PJ Strauss}

Fakulteit Teologie, Universiteit van die Vrystaat

straussp@ufs.ac.za 


\section{INLEIDING EN PROBLEEM}

Onkunde en onsekerheid oor die rol van die diaken in die kerk van die Here Jesus Christus lei daartoe dat persone in hierdie kerklike amp sonder klarigheid oor die soort diens wat van 'n diaken verwag word, by enige soort dienswerk in die gemeente of die kerkverband betrek word. Miskien versterk die woord "diaken" wat met die Griekse "dienaar" (diakonos) in verband gebring word, die indruk van 'n algemene diens wat in die kerk gelewer word.

Hierdie onsekerheid word waarskynlik ook gevoed deur 'n groter beweeglikheid rondom die inhoud, geslag en deelname aan die regering van die kerk in die geskiedenis van die diakenamp. Daar is by die diakenamp 'n groter beweeglikheid rondom ampsfunksies as by die bedienaar van die Woord of die ouderling (vgl Strauss 2013a, 2013b). Die bekende reformator Johannes Calvyn (1509-1564) maak byvoorbeeld gewag van twee soorte diakens, naamlik diegene wat die armes versorg en diegene wat die siekes bystaan. Hy grond dit Skriftuurlik op Romeine 12:8: die wat gee en die wat help en mense bemoedig (Calvyn, sa:63; Kleynhans, 1984:77). Op sy beurt wys Kleynhans op die aanvaarding van die vrou as 'n diakones sonder om haar tot die regering van die kerk toe te laat. Hy wys op die standpunt by talle gereformeerdes wat die vrou tot 'n nie-amptelike hulpdiens of tot die diakenamp, maar nie kerklike regeervergaderings nie, toelaat (Kleynhans, 1984:158-161).

Hierdie artikel kyk na die rol wat twee gereformeerde kerkordes in die Dordtse tradisie aan die diaken toeken: die Kerkorde van die Christian Reformed Church in North America (CRCN-KO) en van die Nederduitse Gereformeerde Kerk (NGKKO). Omdat beide kerkordes bewustelik in die Dordtse tradisie aangepas by die eise van die dag beweeg (Engelhard en Hofman, 2001:13; Strauss, 2010:7; Vorster, 1960:13), word hulle in hierin vergelyk met die rol wat die Dordtse Kerkorde van 1619 (DKO) aan die diaken toeken. Hierdie rol in die gemeente én die kerkverband of die vergaderings van die verband, word uit 'n kerkordelik-kerkregtelike hoek bepreek. Die standpunt van gereformeerde outeurs wat lig op sake kan werk, word ook betrek.

\section{DIE DIAKEN IN DIE CRCN-KO}

Hoewel die CRCN-KO en die NGK-KO bestempel word as twee moderne kerkordes in die Dordtse tradisie, verskil hulle oor die rol van die diaken in die kerk. Dit is egter verskille wat vanuit dieselfde wortel - die Dordtse tradisie - spruit.

Die CRCN-KO en die NGK-KO stem in hulle hoofstukindeling en in sekere frases of formulerings ooreen met die DKO. Hierdie verskynsel, die kerkregtelike beginsels van waaruit beide kerkordes werk en die geskiedenis van die CRCN en die NGK, 
bevestig dat hulle kerkordes bewustelik in die Dordtse tradisie staan (Engelhard en Hofman, 2001:13-17; Vorster, 1960:13, Strauss, 2010:7).

Die CRCN-KO stel die taak van die diaken vas in artikel 25 (Engelhard en Hofman, 2001:151; De Moor, 2010:132).

Kort opgesom verwys Engelhard en Hofman in hulle onlangse kommentaar op die CRCN-KO na die werk van die diaken as "the ministry of mercy" (Engelhard en Hofman, 2001:155). De Moor loop in sy kommentaar van enkele jare gelede op dieselfde spoor. Hy taak die diakens in die gemeente "... to lead the exercise of showing mercy by having those who have plenty supply others with what they need". Volgens De Moor is die diakens daar "to set the tone of servanthood in the church" (De Moor, 2010:136). Hiermee kontinueer albei hierdie kommentare 'n prinsipieelaantoonbare lyn wat via Dordt en die Nederlandse gereformeerde tradisie van die 16e en 17e eeu tot op Calvyn teruggaan (Van Lonkhuizen, 1907:155,157,181,220). Daarmee word nie beweer dat die CRCN-KO die DKO of Calvyn netso - saak vir saak en woord vir woord - oorneem nie, maar dat hy vir die konsep of begrip van 'n Christelike barmhartigheid wat priesterlik bedien word, by beide'n aanknopingspunt vind.

Volgens die CRCN-KO artikel 25 verteenwoordig en organiseer of administreer die diakens die barmhartigheid van Christus onder alle mense, maar veral onder die kerk as die gemeenskap van die gelowiges. Die diakens moet hierdie gemeenskap motiveer om die rentmeesterskap oor hulle bronne of goedere getrou en gehoorsaam tot voordeel van alle behoeftiges binne en buite die kerk, aan te wend. 'n Proses wat gepaard moet gaan met'n Bybelse bemoediging en getuienis aan hierdie mense ten einde die eenheid van woord en daad aan hulle te illustreer (CRCN-KO 2004:9; Engelhard en Hofman, 2001:151).

Volgens Engelhard en Hofman verteenwoordig die kerk Jesus Christus op aarde en beliggaam dit die werking van sy Gees. Christus het siekes, blindes en lammes genees en deernis gehad met die wat terneergedruk of platgeslaan was. Die diakens word geroep om die kerk voor te gaan in dieselfde Christelike (met Christus die Oorsprong daarvan) bediening van barmhartigheid. Die fokus van die kerklike diakonaat is die versameling en verspreiding van geld en goedere vir die behoeftiges (vgl De Moor, 2010:136). Die fokus van hulle roeping is egter nie om die finansiële direksie van die gemeente te wees of die versameling van die gawes van die mense van God nie. Die kern van hulle opdrag is om "Christlike in reaching the distressed" te wees.

"Along with loving deeds and with gifts of money and assistance the deacons are called upon to serve the need with counsel and with assistance, to lead them to see 
the grace of our loving Saviour, and to recognize the Lord from whom all blessings flow" (Engelhard en Hofman, 2001:155).

Die CRCN-KO artikel 25 maak dus nie van 'n diaken 'n suiwer kollektant of bloot 'n organiseerder of administreerder van kerklike fondse nie. Diakonale barmhartigheid of deernis soos die CRCN-KO dit sien, bestaan nie net uit die uitdeel van aalmoese of finansiële hulp aan die armes nie. Dit gaan vir die CRCN-KO om barmhartigheid aan alle mense wat jou pad kruis, mense in fisiese, emosionele en geestelike nood. Die diaken moet Christelike barmhartigheid bedien aan kerklidmate, maar deur hulle en saam met hulle aan alle mense in een of ander vorm van nood.

Hiermee laat die CRCN-KO blyk dat die adres van sy bediening van 'n diakonale barmhartigheid in Noord-Amerika in die $21^{\text {ste }}$ eeu 'n klemverskuiwing ondergaan het. Dit bly steeds diakonale barmhartigheid, maar het weg beweeg van die fokus van 'n soortgelyke bediening in 'n ryk en arm Europa tydens die Reformasie. In die hoogs ontwikkelde en geïndustrialiseerde Verenigde State van vandag, het die behoeftes vir 'n bediening van barmhartigheid van die fisiese na ander soorte armoedes beduidend verskuif. ${ }^{1}$

In hulle bediening van Christelike barmhartigheid moet die diakens, volgens Engelhard en Hofman, as gesante van Christus alle lidmate van die gemeente "in special need" met barmhartigheid bedien: die siekes, behoeftiges, diegene in hospitale, minder bevoorregtes, weduwees en wewenaars (Engelhard en Hofman, 2001: 155). Weereens beperk Engelhard en Hofman die spesiale nood van mense nie tot fisiese armoede nie. Die diakonaat as 'n gemeentelike bediening van Christelike of Christusgeoriënteerde fisiese, geestelike en emosionele barmhartigheid, moet volgens hierdie twee skrywers op alle mense, Christene en nie-Christene, gerig wees. Hulle voorsien ook diakonale werk in kerkverband en vanuit 'n gemeenskapsbetrokkenheid van die kerk (Engelhard en Hofman, 2001:156). De Moor steun hierdie gemeenskapsbetrokkenheid met sy opmerking dat die diakens "prophetic critics of injustice in society at large" moet wees. Hulle moet die belangrikste behoeftes van die breë gemeenskap dapper aanspreek en die gemeente lei om as die mense van God die gemeenskap te dien (De Moor, 2010:136).

Met hierdie kernaanduiding van die taak van die diaken in alle tye, maar, tipies van 'n kerkorde, ook gekonkretiseer in 'n bepaalde situasie en tyd (Strauss, 2010:20), bly die CRCN-KO in die $21^{\text {ste }}$ eeu op die gereformeerde lyn. Die CRCN-KO stel by

1 Lekkerkerker beweer reeds in 1971 dat die ou bedeling sedert die Tweede Wereldoorlog radikaal deurbreek is en dat sake soos gesins- en maatskaplike sorg, 'n regverdige samelewing en ruimte vir elke mens om te leef en te werk, die "doelstellingen ... van de arbeid der diakonie" geword het, 1971:168. 
implikasie dat die opdrag van die diaken "in beginsel” om Christelike barmhartigheid draai, maar dat die adres en praktiese besonderhede van hierdie barmhartigheid skuif met die verandering van die tye en die situasie.

Die CRCN-KO maak'n onderskeid tussen - soos wat dit in die Dordtse geskiedenis genoem is - die breë en die smalle kerkraad. In CRCN-terme word die smalle kerkraad 'n "consistory" en die breë kerkraad 'n "council" genoem. Slegs die predikante en die ouderlinge vorm die "consistory". Hierdie vergadering hou hom besig met kerkregeertake of sake wat die tipiese sake van die ouderling is. Die diakens vorm deel van die "council". Hierdie vergadering hanteer die gemeenskaplike administrasie van die gemeente soos die beroeping van 'n predikant, die aanvaarding van nominasies vir die kerklike ampte, ontmoetings met die visitatore van die klassis en sake van gemeenskaplike belang. In gemeentes waarin daar minder as 4 ouderlinge is, word die onderskeid tussen 'n "consistory" en 'n "council" nie getref nie. Hier dien die ouderlinge en die diakens van die gemeente saam op die kerkraad om 'n ongereformeerde, hiërargiese oligargie of besluite vir die gemeente deur net 'n klein groepie uit te skakel (Engelhard en Hofman, 2001:221-222).

Wat die regering van die kerk op meerdere vergaderings betref, kan elke gemeente een predikant, een ouderling en een diaken na die klassis afvaardig. Laasgenoemde word egter net afgevaardig indien die betrokke klassis so besluit (Engelhard en Hofman, 2001:247). Op sy beurt vaardig elke klassis 2 predikante en 2 ouderlinge af na die sinode van die CRCN. Die diakens is hiervan uitgesluit (Engelhard en Hofman, 2001:267).

\section{DIE DIAKEN IN DIE NGK-KO}

Getrou aan dit wat tot dusver in hierdie artikel gesê is, dra die bepalings van die NGK-KO oor die diaken 'n duidelike Dordtse spoor. Hierdie spoor is sigbaar in die feit dat die NGK-KO die opdrag van die diaken - soos die CRCN-KO - tot 'n groot mate sentreer rondom die diens of die "bediening" van barmhartigheid.

Volgens die NGK-KO is die diaken verantwoordelik vir die "opheffing, vertroosting en ondersteuning van almal wat in of ander opsig barmhartigheidsdiens benodig". Hierdie bepaling in NGK-KO 2013 kom, behalwe vir 'n enkele woordwysiging, onveranderd deur vanaf NGK-KO 1962. Laasgenoemde was die eerste NGK-KO wat by die vorming van die eerste algemene sinode van die NGK aanvaar is (NGK-KO, 1962:4; NGK-KO, 2013:6). Bloot semanties beskou, gee die woorde "in een of ander opsig barmhartigheidsdiens benodig" dieselfde gedagte oor barmhartigheidsdiens weer as die CRCN-KO. "In een of ander opsig" beteken immers dat dit hier nie 
net om liggaamlike of fisiese nood gaan nie, maar enige menslike nood: fisies, emosioneel en geestelik.

Drie van die vyf bepalings in die NGK-KO oor dit waarop die "amp of bediening" van die diaken gerig is, draai om die "bediening" van barmhartigheid. Behalwe bogenoemde bepaling ten opsigte van barmhartigheidsdiens "in een of ander opsig", is die diaken getaak met die "organisering en leiding" van die barmhartigheidsdiens in die gemeente. Daarby moet die diakonie sorg vir die "insameling en besteding" van middels wat vir die diakonale werk in die gemeente nodig is (NGK-KO, 2013:6).

Die woorde dat die diaken in sy "bediening gerig" is, kom uit 1998. Dit volg op 'n verslag van $A B$ du Toit waarin hy 'n oortuigende onderskeid tref tussen die ampte of, soos hy dit verkieslik noem, "bedieninge", en die foci of bedieningsfunksies van die ampte. Volgens hom is die foci die konstantes in die bediening van die kerk en die ampte die tydgebonde uitvoering of bediening van hierdie foci. Die ampte diens hierdie foci of is daarop gerig. Du Toit onderskei 3 "hoof-foci" vir die kerklike ampte: geestelike leiding en toesig wat die ouderling fokus, praktiese dienswerk wat die diaken en Woordbediening wat die predikant fokus. Woorde soos "praktiese dienswerk" en "gerig op" word in 1998 in die NGK-KO opgeneem. Volgens Du Toit kan daar onder elke fokus van tyd tot tyd meer as een bediening of amp ingestel word. Die volhoubaarheid en aanvaarbaarheid van so 'n amp hang af van sy volhardende effektiewe gerigtheid op of diens aan sy bepaalde fokus. Hierdie 3 foci "val in belangrike opsigte saam" met die profeet, priester en koning van die $\mathrm{Ou}$ Testament en die drieledige amp van Jesus Christus wat ons as ons "hoogste Profeet en Leraar", "enigste Hoëpriester" en "ewige Koning" bedien (NGK 1998:220-221; NGK-KO, 1998:8; Heidelbergse Kategismus Sondag 12, NG Kerk-Uitgewers sa:47). Daarmee gee die 3 foci erkenning aan die belydenis dat Jesus Christus vanuit hierdie drie ampte die Hoof van die kerk is (vgl Jonker 1965:3 vir die belydenis dat Christus die Hoof van die kerk is).

Ten opsigte dit waarop die "amp of bediening" van die diaken gerig is, openbaar die NGK-KO egter ook 'n tendens wat by van sy ander bepalings deurslaan: dit legitimeer of sanksioneer verskynsels uit die teenswoordige praktyk. 'n Tendens wat die orde van die kerk nie vanuit of op grond van 'n konstante of Skriftuurlike beginsel bedryf nie (die ius constituendum), maar op grond van bestaande gebruike in die kerklike praktyk (die ius constitutum, Kleynhans, 1984:5).

NGK-KO artikel 17 wat oor die gerigtheid van die diaken handel, stel ter inleiding ongekwalifiseerd dat hierdie "amp of bediening" gerig is op "praktiese dienswerk". Dit begin in die erediens en kring vandaar uit na die gemeente en die wêreld waarin die lidmaat leef. Terselfdertyd maak die artikel 'n saak uit vir die diaken as gerig 
op barmhartigheidsdiens. Behalwe barmhartigheidsdiens, "omvat" die diakenamp volgens die NGK-KO egter ook "toerusting van lidmate vir hulle dienswerk". Hierby moet die diaken ook "ander opdragte" wat die kerkraad aan hom gee, uitvoer. Die kerkraad bepaal, met 'n inagneming van hierdie take van die diaken, die bedieningsverantwoordelikheid van die diaken (NGK-KO, 2013:7; vgl die terme van Du Toit).

Naas diakens se barmhartigheidsdiens word hulle bediening dus veralgemeen tot ongekwalifiseerde "praktiese dienswerk". Hulle moet die gemeente ook toerus vir hulle dienswerk en gereed wees vir enige opdrag wat die kerkraad aan hulle kan gee. Hierdie benadering spruit waarskynlik meer uit die ervaring van die praktyk in baie NGK-gemeentes as 'n duidelike Bybelse beginsel.

Eerstens is hier 'n vaag omlynde onderskeid tussen "praktiese" dienswerk en barmhartigheidsdiens. Algemene "praktiese" diens relativeer die diakenamp as primêr gerig op barmhartigheidsdiens. Dit taak die diaken vir die praktiese uitvoering van enige iets in die gemeente. So verword hierdie amp tot 'n posbus vir algemene "praktiese" take. Tweedens neem die diaken hier 'n deel van die opdrag van die bedienaar van die Woord oor naamlik die toerusting van lidmate vanuit die Woord van God. Toerusting wat hierdie kerklik erkende kundige van die Woord in die gemeente moet onderneem om te verseker dat die kerk, kerk van die Woord is. Gelet op die woorde "praktiese dienswerk" as 'n moontlike kerklike begrip, is dit in elke geval 'n vraag of hierdie toerusting onder die begrip "prakties" soos hier gebruik, kan tuiskom.

Daarmee sanksioneer die NGK-KO 'n praktyk waarin die spesifieke van die amp van diaken nie duidelik onderskei en in ag geneem word nie. Die wyd beoefende posbusidee van die diakenamp vir enige taak wat in die gemeente onderneem moet word, word eenvoudig sonder 'n fyn onderskeid tussen die werk van die lidmate en die ampte en die ampte onderling, in die bepalings van die NGK-KO opgeneem. Wat hierdie skuif kan versag, is die woorde "praktiese dienswerk2", met die klem op "diens", wat hiervoor gebruik word. Die tergende vraag is egter: is enige dienswerk nie "prakties" nie? Of is sekere soorte werk - soos die bediening van die Woord onprakties?

Steeds by die NGK-KO en die gerigtheid van die diakenamp: leen hierdie onduidelike "verbreding" van die amp van die diaken hom nie daartoe dat hierdie amp as gevolg

2 Kleynhans bestempel die amp van die diaken as 'n amp met 'n "stempel van sy eie", 1984:76. 
van sy identiteitloosheid rondom die diens van barmhartigheid, deur vrouegroepe en vrywillige verenigings vervang word nie?

NGK-KO artikel 17 begin ook met die stelling dat die praktiese dienswerk van die diaken begin in die erediens. Van daar gaan dit uit na die kerk en die wêreld (NGKKO 2013:6). Kleynhans vereenselwig hom hiermee met die opmerking dat die diens wat in Handelinge 6 aan die diakens "toevertrou" is, "oorspronklik" beteken het om die gawes wat inkom te ontvang, die tafels vir die liefdesmaaltye en die nagmaal gereed te maak en die dankoffers na die maaltyd uit te dra na die armes en die siekes wat die nagmaal nie kon bywoon nie (Kleynhans, 1984:80). NGK-KO artikel 17 koppel hierdie bepaling implisiet aan Handelinge 6.

\section{DIE DIAKEN IN DIE DKO}

Die vraag is natuurlik: hoe vergelyk die CRCN-KO en NGK-KO se bepalings oor die rol van die diaken in die kerk met die van die DKO? Is die CRCN-KO en NGK-KO op hierdie punt ook kerkordes in die Dordtse tradisie?

Wat onmiddellik opval, is dat die CRCN-KO sy bepaling van die "ambt" of "dienst" van die diaken (die DKO gebruik albei hierdie terme, Pont, 1981:176,179), soos die DKO in 1619 , vervat in artikel $25 .^{3}$ Dit op sigself dui al op 'n bewuste band met die DKO. Daarby gebruik die DKO reeds in 1619 sekere sleutelbegrippe vir die bediening van die diaken wat tot 'n mindere of meerdere mate deur die $\mathrm{CRCN}-\mathrm{KO}$ en die NGK-KO oorgeneem word.

Die DKO maak gewag van die diakens wat "aalmoezen en andere armengoederen naarstichtelijk" moet versamel en dit moet uitdeel na die "eisch der behoeftigen". "De benauden" moet ook besoek en vertroos word. Hierdie uitdeelaksies moet onder "ingezetenen en vreemden, met gemeen advies" plaasvind. Dit gaan hier dus om goedere aan die armes binne en buite die gemeente, maar ook troos en advies aan die wat benoud of onder druk is (Pont, 1981:179). Die DKO roer dus reeds die saak van die bediening van barmhartigheid aan vir die wat dit benodig, asook die kwessie van troos as 'n middel teen geestelike nood, aan. Die diakens is ook verantwoordelik vir die versameling en uitdeel van goedere teen armoede.

Die DKO se invloed is sigbaar in die CRCN-KO se verwysing na die organisering van die bediening van barmhartigheid en troos aan almal, veral lede van die geloofsgemeenskap, in fisiese en geestelike nood: na die "needy" se vertroosting deur

3 Vgl Visser, 1999:108. Dit is interessant dat die Kerkorde van die Gereformeerde Kerke in Suid-Afrika en die CRCN-KO wat albei die DKO doelbewus navolg, dit op hierdie punt ook in sy artikel 25 doen. 
woord en daad. Ten opsigte van die troos van die DKO praat die CRCN-KO van "words of biblical encouragement and testimony". Waar die NGK-KO handel oor die "bediening" van barmhartigheid aan "almal (wat) dit in een of ander opsig" nodig het, sluit hy in belangrike opsigte by die DKO aan. Hy praat van die vertroosting van almal wat dit nodig het, die diakens wat die middels vir barmhartigheid moet insamel en bestee en hulle organisering van die barmhartigheidsdiens of -bediening van die gemeente. Sy verwysing na "praktiese dienswerk" kry die NGK-KO egter nie by die DKO nie.

Hoewel die DKO nie van barmhartigheidsdiens of "the mercy of Christ" praat nie, is die saak waarop hy afstuur die bediening van barmhartigheid aan die armes en geestelik en emosionele bedruktes. Wanneer die CRCN-KO en die NGK-KO dit dus oor die rol van die diaken in die kerk het, loop hulle in die kern op Dordtse spore.

In sy uitgebreide kommentaar op die DKO plaas De Gier die bepalings van die DKO artikel 25 in 'n verduidelikende konteks. Volgens hom moes veral die armes in die gemeente, maar daarnaas alle behoeftiges wat die pad van die kerk kruis, uit liefde deur middel van "liefdegaven" versorg word. As begronding gee hy Galasiërs 6:10 wat vanaf Calvyn via die destydse bevestigingsformulier vir diakens hierdie bepaling in die DKO sou beïnvloed het. Dit gaan om die bediening van barmhartigheid vanuit harte wat omgee en wat omgesit word in gawes wat aan die armes uitgedeel word. Liefdesgawes wat De Gier onderskei van "kerkelijke bijdragen" in die algemeen as, soos hy dit stel, 'n "kerkelijke verplichting". Liefdesgawes wat "meer een zedelijke verplicting" en beslis ook iets totaal anders as staatsbelasting is (De Gier, 1989:138,140).

Ten opsigte van die bepaling in die DKO dat die diakens die "benauwden" moet besoek en vertroos, wys De Gier daarop dat die besoek van die diaken 'n vorm van huisbesoek is, maar in sy aard verskil van die besoek van die ouderling. Dit is 'n besoek na aanleiding van en gerig op die "nood der behoeftigen". Dit gaan om 'n bediening van barmhartigheid, nie alleen deur die uitdeel van stoflike gawes nie, maar ook 'n "woord of gebed van troost". Die diaken moet oor die lewenswysheid beskik om "vertrouwelijk" met die behoeftiges te kan praat oor geestelike en maatskaplike toestande. Hy of sy moet in bepaalde gevalle raad gee, maar soms ook vermanend en bestraffend optree (De Gier, 1989:143).

Die slotsom waartoe De Gier dus kom, is dat die fokus van die diaken die van 'n priester in diens van Christelike en kerklike barmhartigheid moet wees, maar dat dit hom of haar nie moet verhoed om - indien nodig - ook koninklik en profeties op te tree nie. Hierdie drie ampte kan onderskei, maar nie geskei word nie. Dit is moontlik omdat hulle in 'n Christosentriese kerklike bediening afwisselend die 
fokus in 'n situasie vorm. Saam vorm hulle die omvang van die kerklike bediening waarvan Christus as Hoof ons "hoogste Profeet en Leraar", "enigste Hoëpriester" en "ewige Koning" is (Heidelbergse Kategismus Sondag 12, NG Kerk-Uitgewers, sa:47).

Die "gemeen advies" waarmee hierdie barmhartigheid volgens die DKO moet plaasvind, beteken dat die diakonie as groep of vergadering met mekaar ooreenkom oor wat waar gegee moet word. Terselfdertyd bepaal die DKO dat die diakonie verantwoording doen aan die kerkraad vir sy doen en late. Dat die kerkraad as die regeervergadering van die gemeente, die finale seggenskap het oor die diakonaat, maar dat die diakens op hierdie deel van die kerkraad as die "council" sitting het (De Gier, 1989: 141,142,144).

Die samevatting van wat die CRCN-KO en die NGK-KO as twee kerkordes in die Dordtse tradisie oor die rol van die diaken in die kerk bepaal, word goed in artikel 25 van eersgenoemde raakgevat: die bediening van die diaken is "the ministry of mercy". Die CRCN-KO verwoord hierdie rol in 'n bepaling wat sedert die Dordtse Nasionale Sinode van 1618-1619'n suiwering deurloop het en in die moderne tyd steeds as geldig beskou word. Hiermee gee hierdie twee kerkordes in die verlengde van die DKO of as die DKO "aangepas by die eise van die dag", blyke van die bediening van barmhartigheid as die fokus van die diakenamp of diakonale diens. Dit erken ook die noodsaak van die bediening van die Woord in dieselfde proses en van 'n diakonale ywer vir 'n regverdige samelewing waarbinne mense kan leef en werk. 'n Regverdige samelewing wat 'n natuurlike konsekwensie van gehoorsaamheid aan die Woord is (Lekkerkerker, 1971:168).

In 'n meer onlangse werk van gereformeerdes onder redakteurskap van Koole en Velema, Zichtbare liefde van Christus - Het diakonaat in de gemeente, word hierdie lyne in die Dordtse tradisie opnuut bevestig. Velema is 'n voorstander van 'n "evangelische" motivering vir diakonale hulpverlening waarin "die humaniteit" opgeneem is. 'n Hulpverlening wat volgens hom nie slaag as die verhouding met God nie herstel word nie. Vir hierdie herstel het God sy Seun gestuur. God se liefde wat Hy so geopenbaar het, het ons gered en stuur ons om ander te red. 'n Teken van hierdie reddende liefde is "diakonale dienstbetoon" (Velema, 1991:215). Vir Velema is die verhouding tot God en tot mekaar twee aspekte wat God in sy liefde herstel. Al twee hoort in die visier van die diakonaat (Velema 1991:214). Waar Velema se evangeliese motivering duidelik is, is sy gebruik van die begrip humaniteit waarskynlik gemik op dieselfde saak as 'n regverdige samelewing waarbinne mense kan leef en werk.

Biesterveld en Meyenfeldt sluit uit 'n gereformeerde hoek hierby aan. Vir eersgenoemde dra die diakonaat as armsorg ook'n geestelike en moreel Christelike karakter. Dit moet deurdring tot die verhoudings waarin 'n mens leef (Biesterveld, 
1907:232). Vir laasgenoemde is diakonale hulp diens van barmhartigheid. Hy haal Dijk aan wat aanvoer dat die diakenamp deur die daad Christus se liefde en ontferming illustreer. 'n Liefde wat red en herstel: mensomvattend (Von Meyenfeldt 1955:22).

\section{DIE DIAKEN EN KERKVERGADERINGS}

In die gemeente onderskei Engelhard en Hofman tussen die sogenaamde consistory (predikante en ouderlinge) en die council (die consistory plus die diakens). Die council hanteer die gemeenskaplike sake van die gemeente terwyl die consistory hom besighou met die sake waarop die amp van die ouderling gerig is (Engelhard en Hofman, 2001:221). Laasgenoemde gaan oor dinge soos die opsig oor die leer en lewe van alle gemeentelede naamlik ampsdraers en nie-ampsdraers, die kerklike tug in en pastorale versorging van die gemeente, die verdediging van die geloof en evangelisasie.

Die diakens wat van die consistory uitgesluit is, het hulle eie vergadering gerig op die diens van barmhartigheid naamlik die diakonaat (Engelhard en Hofman 2001:151).

Hierdie onderskeid word voorafgegaan deur die bepaling van 'n breë (ouderlinge en diakens) en smalle kerkraad (ouderlinge) in die DKO en Dordtse tradisie. 'n Saak waarop reeds gewys is. Die gangbare motivering was dat die ouderling die koninklike amp van Christus verteenwoordig en hom daarom met die kerkregering moet besighou, terwyl die diaken priesterlike diens verrig en daarvan uitgesluit is.

Twee bepalings in die DKO self het hierdie onderskeid egter gerelativeer. Die eerste is artikel 38 wat bepaal dat die diakens deel uitmaak van 'n kerkraad waar die getal ouderlinge "zeer klein" is. Die gedagte was om die hiërargie of heerskappy van 'n klein groepie in die gemeente te voorkom. As 'n gereformeerde moes kies tussen kerkregering as suiwer 'n taak van ouderlinge en 'n niehiërargiese benadering, kry laasgenoemde voorkeur. In so 'n geval kan die diaken koninklik optree. Die tweede is DKO artikel 25 wat bepaal dat die diakens die "benauwden" moet vertroos (profeties deur die Woord van God) en moet toesien (koninklik, regerend) dat die aalmoese wat hulle ontvang, nie misbruik word nie (Pont, 1981:179,180). Hierdie bepaling het die deur geopen vir die opvatting dat die bediening van die Woord deel uitmaak van die diaken se barmhartigheidsdiens. Dit sou van die diaken ook 'n profetiese draer van die Woord maak. Wat hierdie bepalings dus uitwys, is dat jy die profetiese, priesterlike en koninklike ampte nie van mekaar kan isoleer nie. Dieselfde ampsdraer word soms geroep om in dieselfde situasie afwisselend profeties, priesterlik en koninklik op te tree. Die omstandighede bepaal die manier van optrede of hoe en waarvoor die Woord gebruik word. 
Met die vorming van die eerste kerkraad in 'n NG Kerk, die kerkraad van Kaapstad in 1665, is DKO artikel 38 gevolg. Dit kon nie anders nie, omdat ds Joannes van Arckel, ouderling Abr Schut en diaken Joan Reinierszen die enigste kerkraadslede was (Van der Watt, 1976:8). 'n Smalle kerkraad van 2 sou eenvoudig te klein wees. Wat hier as 'n uitsondering hanteer is, het egter sonder sigbare verdere besinning die praktyk in die NG Kerk geword. Die diakens sou deel van die Kerkraad van Kaapstad bly en nuwe gemeentes die voorbeeld volg. Daarmee het die NG Kerk vanaf die ontstaan van die eerste gemeentes aan die Kaap die tendens ontwikkel om hom kerkregtelik deur die bestaande praktyk in plaas van gedebatteerde beginsels te laat lei. Interessant genoeg het dieselfde kerk eers in resente tye diakens tot meerdere vergaderings toegelaat. Hulle kon tot in die 1980's in die gemeente regeer, maar nie in kerkverband nie. Na hulle opname in die meerdere vergaderings van die NG Kerk was daar egter nie 'n bepaling wat 'n gelyke getal ampte per gemeente by hierdie vergaderings waarborg nie (NGK-KO 1986:8,9). 'n Gelykte aantal van elke amp is immers 'n ou gereformeerde beginsel om geen amp oor 'n ander te laat heers nie (Strauss, 2010:52). Hier is gedebatteerbare beginsels ook nie gebruik nie.

Die sitting van diakens in meerdere vergaderings word in resente tye deur byvoorbeeld Lekkerkerker en Van't Spijker ondersteun. Eersgenoemde bepleit geen "subordinatie" nie, maar 'n "korrelatie" tussen die ampte (Lekkerkerker 1971:171). Laasgenoemde wys daarop dat meerdere vergaderings dikwels sosiale vraagstukke hanteer waarin diakens die kerklike kundiges is. En juis omdat die fokus van die ampte van mekaar te onderskei, maar nie te skei is nie, kan diakens 'n goeie bydrae op hierdie vergaderings lewer (Van’t Spijker, 1991:193).

\section{SLOT}

Van die ouer gereformeerde teoloë is oortuig dat Handelinge 6 se verwysing na die aanwysing van die 7 wat die Griekssprekende weduwees moes versorg, die instelling van die diakenamp verhaal (Kleynhans, 1984:74). Steenbergen formuleer versigtiger en waarskynlik meer korrek. Volgens hom is daar probleme om die instelling van die diakenamp as 'n geïndiwidualiseerde amp na Handelinge 6 terug te voer. Tog sien hy in Handelinge 6 'n vertakking van dienste met die uitgroei van 'n diens met diakonale motiewe uit die een amp, die van apostel. 'n Vertakking wat 'n stap verteenwoordig in die rigting van die instelling van die diakenamp (Steenbergen, 1991:31) en so vir die fokus van 'n priesterlike barmhartigheidsdiens 'n handige toepassing gee.

Hoe dit ook al sy. $\mathrm{Al}$ is daar nie klarigheid oor die instelling van die diakenamp nie, die CRCN-KO en die NGK-KO as twee kerkordes in die Dordtse tradisie formuleer hierdie amp as gerig op Christelike barmhartigheid aan hulle wat in nood verkeer, 
baie duidelik. ${ }^{4}$ Dit gaan hier om kerkordelike bepalings wat in essensie na die DKO van 1619 teruggevoer kan word. Om 'n erkende kerklike amp wat aan geen ander amp ondergeskik is nie.'n Amp in wie se bediening of in sy diens van barmhartigheid die Woord van God rigtinggewend moet wees.

BIBLIOGRAFIE

Biesterveld, P 1907. Het diaconaat in zijne uitoefening. In: Biesterveld, P, van Lonkhuizen, J en Rudolph, RJW. Het Diaconaat Deel II. Hilversum: JH Witzel. Calvyn, J sa. Institutie III. Delft: WD Meinema (vertaling van A Sizoo).

CRCN (Christian Reformed Church in North America) 2004. Church order and rules for synodical procedure. Grand Rapids: CRCN.

De Gier, K 1989. De Dordtse Kerkorde. Een praktische verklaring. Houten: Den Hertog.

De Moor, H 2010. Christian Reformed Church Order Commentary. Grand Rapids: Faith Alive.

Engelhard, DH en Hofman, LJ 2001. Manual of Christian Reformed Church Government. Grand Rapids: CRC Publications. Harmannij, K 1990. Wegwijs in de kerkorde. Barneveld: De Vuurbaak.

Jonker, WD 1965. Om die regering van Christus in sy kerk. Pretoria: Unisa.

Kleynhans, EPJ 1982. Gereformeerde Kerkreg I. Pretoria: NG Kerkboekhandel Transvaal.

Kleynhans, EPJ 1984. Gereformeerde Kerkreg II. Pretoria: NG Kerkboekhandel Transvaal.

Lekkerkerker, AFN 1971. Oorsprong en funktie van het ambt. Den Haag: Boekencentrum.

NGK (Nederduitse Gereformeerde Kerk) 1998. Agenda Algemene Sinode. Sl:sn.

NGK-KO (Nederduitse Gereformeerde Kerk - Kerkorde) 1962. Pretoria: NG KerkUitgewers.

4 Vir dieselfde standpunt by die Gereformeerde Kerke in Nederland (Vrygemaak), kyk Harmannij, K 1990:18. 
NGK-KO (Nederduitse Gereformeerde Kerk - Kerkorde) 1986. Pretoria: NG Kerkboekhandel Transvaal.

NGK-KO (Nederduitse Gereformeerde Kerk - Kerkorde) 1998. Wellington: Hugenote Uitgewers.

NGK-KO (Nederduitse Gereformeerde Kerk - Kerkorde) 2013. Sl:sn.

NG Kerk-Uitgewers sa. Die Heidelbergse Kategismus. Wellington: NG KerkUitgewers.

Pont, AD 1981. Die historiese agtergronde van ons kerklike reg. Pretoria: HAUM.

Steenbergen, W 1991. Het Nieuwe Testament - Handelingen en brieven. In: Koole, D en Velema, WH. Zichtbare liefde van Christus. Kampen: Kok Voorhoeven, 23-42.

Strauss, PJ 2010. Kerk en orde vandag. Bloemfontein: Sunmedia.

Strauss, PJ 2013a. Die bedienaar van die Woord in twee kerkordes in die Dordtse tradisie. TCW 19/4: 295-308.

Strauss, PJ 2013b. Die ouderling in twee kerkordes in die Dordtse tradisie. Acta Theologica 33/1: 240-251.

Van der Watt, PB 1976. Die Nederduitse Gereformeerde Kerk 1652-1824. Pretoria: NG Kerkboekhandel.

Van Lonkhuizen, J 1907. De geschiedenis van het diaconaat. In: Biesterveld, P, Van Lonkhuizen, J en Rudolph, RJW. Het diaconaat I. Hilversum: JH Witzel.

Velema, WH 1991. Diakonale roeping. In: Koole, D en Velema, WH. Zichtbare liefde van Christus. Kampen: Kok Voorhoeven, 196-221.

Visser, J 1999. Die kerkorde in praktyk. Orkney: EFJS.

Von Meyenfeldt, FH 1955. De diaken als componist der gemeenschap. Den Haag: Van Keulen.

Vorster, JD 1960. Die kerkorde van die NG Kerke. NGTT 1/4, 12-18.

Van’t Spijker, W 1991. De diaken en de kerkelijke vergaderingen. In: Koole, D, en Velema, WH. Zichtbare liefde van Christus. Kampen: Kok Voorhoeven, 192195. 
